\title{
Is Three a Crowd in Reproduction? (The Authorization of Mitochon- drial Donation in the UK)
}

\author{
Vera Lúcia Raposo ${ }^{1,2}$ \\ ${ }^{1}$ Law School, University of Macau, Macau, China \\ 2Law School, Coimbra University, Coimbra, Portugal
}

\begin{abstract}
Regulations recently passed in the UK to allow mitochondrial donation through artificial reproductive techniques have heated up the debate about this procedure, which in the near future may be extended to other parts of the world. Detractors of mitochondrial donation invoke the excessive risks inherent to the very novelty of the procedure and the lack of knowledge of its consequences. In the ethical and legal context, the main concerns relate to motherhood determination, the notion of social individuality, its association with genetic manipulation and all the issues accompanying it, the risk of opening the door to more dangerous practices, the potential discrimination toward existing individuals suffering with mitochondrial diseases, the fact that the same outcome - preventing the transmission of mitochondrial diseases - can be achieved by means of less risky procedures, and the modification of the genetic pool of humanity. However, most of the underlined risks are more uncertain than actual, and, indeed, natural to every new technique. Considering the major benefits offered by the procedure, and as long as we act under the auspices of the principles of precaution and prevention, there are no obstacles to the transference of mitochondrial material through artificial reproductive techniques.
\end{abstract}

Keywords: Mitochondrial donation, Mitochondrial DNA, Parenthood, Identity, Genetic manipulation, Artificial reproductive techniques

\section{The notion of mitochondrial donation}

Recently, the UK became involved in a heated discussion around the so-called "mitochondrial donation" or "mitochondrial transference" procedures. The discussion has gone international, and regulatory agencies in other countries such as the Food and Drug Administration in the United States have been looking into the matter. But what is mitochondrial donation and what is it for?

Mitochondria can be found in the cytoplasm (the material surrounding the nucleus of the cells and that directly affects reproductive function) of almost any human cell, in numbers ranging from several tens to thousands. They possess their own genetic material, but they play no role, according to scientific consensus, in the determination of one's characteristics (Wellcome Trust, 2014), but rather in the generation of most of the energy supplied to the cell. Mutations in mitochondrial genes may have serious effects and impair the production of energy to cells and tissues, giving rise to neurodegenerative diseases, stroke-like episodes, blindness, muscular dystrophy, diabetes, deafness, and cause the death of newborns, children, and young adults. In other words, the human body needs healthy mitochondria to fend off a wide range of mild, extremely debilitating, and even deadly conditions. Transmitted exclusively by the maternal route, it is estimated that one in 6,500 children will develop a severe mitochondrial disorder (Wellcome Trust, 2014), for which there is no cure and whose symptoms cannot be successfully managed (Barber \& Border, 2015; HFEA, 2014).
Mitochondrial DNA opposes to nuclear DNA, which amounts to $99.9 \%$ of the total cell DNA and carries the vast majority of our genes, shapes our physical characteristics (including appearance), and contributes to our personality (along with education and environment). Unlike mitochondrial DNA, these genes are inherited from both genetic parents.

Mitochondrial donation is a procedure carried out through assisted reproductive techniques designed to prevent the birth of people with inherited mitochondrial diseases. It precludes the transmission of these diseases through the transfer of the cytoplasm of a "normal" oocyte into another oocyte that does not meet the requirements necessary for the birth of a healthy baby.

It is performed via various procedures, the most developed of which being maternal spindle transfer (MST) and pro-nuclear transfer (PNT). Mitochondrial donation is carried out through a modified version of in vitro fertilization, an assisted reproductive technique (ART). The nuclear DNA of the patient - the female element of the couple and future biological and legal mother - is transferred to the enucleated oocyte of a donor (not considered the biological mother) equipped with healthy mitochondria. In MST, the nuclear DNA is removed from the donor egg, leaving the part of the cell containing the healthy mitochondria. The nuclear DNA from the patient's egg is then inserted into this cell. The oocyte resulting from the fusion of genetic materials is then fertilized with the sperm of the male partner, who is both the genetic and legal father. Differently, in PNT the patient's egg is first fertilized and only then its mitochondria are substituted with the healthy donor's mitochondria.

Both procedures generate a child whose genetic heritage matches almost $100 \%$ that of their parents, with the exception of the mitochondrial genes. Strictly speaking, the new being will be formed from the genetic contributions of three persons: the two members of the couple and the donor. Thus, the embryo will inherit 23 chromosomes from the father, 23 chromosomes from the mother, and the mitochondrial chromosomes of the donor's mitochondria. The only way to overcome this triple contribution is by inviting a female donor maternally related to the patient. However, in addition to possible problems of anonymity, this hypothesis raises questions over the effectiveness of such procedure. In fact, since the purpose of mitochondrial replacement is to prevent the vertical transmission of diseases caused by mutations in mitochondrial DNA, it is very likely that a female donor related to the patient will convey the same mutations to the child.

This discussion is far from new. In the UK the focus of this controversy dates back to at least 2010, when the licensing of mitochondrial donation was first proposed. In the years of 2011, 2013, and 2014, at the request of the British Government, the Human Fertilization \& Embryology Authority (HFEA) carried out three scientific reviews on this technique and found no evidence suggesting it was unsafe for clinical use. The matter was also brought to pub- 
lic discussion (HFEA, 2013), and public support was quite evident. Finally, regulations authorizing the procedure in the UK went into effect in February 2015, sparking intense discussions around the world.

\section{When is the procedure useful?}

Mitochondrial donation can occur for reasons other than preventing the transmission of cytoplasmic diseases.

It is particularly useful when a female homosexual couple wishes to have a child that shares the genetic material of both women. Though it is necessary (at least in the present state of technique) to resort to sperm donation, it is possible (scientifically possible, legal admissibility varies depending on the legal system) to produce a child that combines the DNA of both women. In order for both women to be genetically connected to the child, the oocyte nucleus of one and the oocyte cytoplasm of the other have to be used in the process.

Another alternative application of this technique is in the rejuvenation of oocytes belonging to women considered reproductively old, since they would have trouble conceiving using their own oocytes due to the increased count of mutant mitochondria resulting from their age.

However, in this review we will not refer to these situations. Although they use the same techniques and raise many of the same concerns, they have a distinct social contextualization and, for that reason, a different legal framework. Therefore, we will only cover mitochondrial donation designed to prevent the transmission of inherited diseases of a mitochondrial nature (note that the inverse technique can also be used by women with a healthy cytoplasm and diseased nuclear DNA; if they wish to have a child genetically linked to them, albeit minimally, they may resort to nuclear oocyte donation).

\section{A legitimate procedure?}

Criticism to the admissibility of mitochondrial donation essentially underlines the risks of the procedure from the medical, ethical, and legal perspectives. However, most of the points raised by critics are hardly realistic, and barely carry the relevance or yield the consequences listed by them, as we shall demonstrate.

\section{Medical risks}

Medical risks basically include the dangers inherent to procedures not yet fully consolidated.

It is a fact that scientists still do not master all the consequences of this "mitochondrial meddling" in the life of the embryo and its progeny (Knoepfler, 2014; Nuffield Council on Bioethics, 2012; Taylor, 2015), and that some scientist have invoked precedents suggesting that negative results are reasonably likely, without precisely identifying their causes (Dong et al., 2006).

In the last century some fertility clinics in the US (Kolata, 2001) and China (Pearson, 2003), among other countries, carried out procedures of human reproduction similar to mitochondrial transfer and detected potential anomalies.

For this reason, the detractors of the procedure claim that although today's mitochondrial transfer technology has been relatively improved, there is no clear evidence indicating that the potential losses will be entirely avoided with the use of new technology.

Perhaps it was the awareness of these risks that led the HFEA to recommend that the daughters of women (given that mitochondrial DNA is transmitted only maternally) born by this procedure should undergo preimplantation genetic diagnosis (PGD) to select their embryos, in order to ensure that those embryos did not carry mitochondrial mutations and prevent the occurrence of adverse side effects in future generations (HFEA, 2013).
A possible cautionary measure to this end would be to select only male embryos, since the donated mitochondrial DNA would be passed on solely to female babies. Regarding the male infants resulting from this technique, though they are also carriers of the mitochondrial DNA, they cannot pass it on to their offspring, once it is transmitted only by the maternal route. It is a fact that this procedure would translate into gender selection, a very controversial practice itself. However, in this case the selection would derive from therapeutic motivations, and would be admissible in most legal orders, according to article 14 of the European Convention on Human Rights and Biomedicine (Paolo et al., 2014; Raposo, 2014).

Another possible risk relates to eventual genetic incompatibilities. Problems may arise because the patient and the donor may have different mitochondrial haplotypes and, for this reason, there is a theoretical risk that the donated mitochondria might fail to properly communicate with the nuclear DNA of the patient, therefore causing problems in the embryo and the resulting child (HFEA, 2014).

An additional risk comes from the fact that a small amount of "sick" mitochondrial DNA from the patient might be transferred together with nuclear DNA to the embryo, thus jeopardizing the entire process. However, in such event the amount of diseased mitochondrial DNA transferred would be so minuscule that it would be very unlikely for the infant to be affected at all (HFEA, 2014).

In sum, various risks may be thought of. The fact is that it is impossible to assure the absolute safety of any medical procedure. What we can conclude after the investigation - and no other reproductive technique was ever subject to such level of scrutiny - is that scientific evidence suggests that the risks of mitochondrial donation are proportionate to the severity of mitochondrial diseases (Wellcome Trust, 2014).

\section{Non-medical risks}

A few other perils should be considered in addition to medical risks, this time of a more ethical and legal nature.

Let us start with the issue of parenting. In fact, it has been pointed out how difficult it is to determine how many mothers the child will have: one or two? Genetic bond is what traditionally determines motherhood - and fatherhood. This basic principle grounds the legal solution in place on the majority of legal orders, according to which juridical maternity is determined by delivery, on the assumption (later on denied by surrogacy) that the woman who gives birth - and only she - is the one who maintains a genetic bond with the child. Apart from the scenarios of gamete donation and gestational surrogacy, genetic ties are still prevalent in juridical motherhood. In addition, the rule is that each child has necessarily one father and one mother and, on the other hand, solely one father and one mother. To a large extent these are still the prevailing rules in most of the legal systems around the world (Bender, 2003; Raposo, 2007).

Nonetheless, these rules suffer exceptions in some jurisdictions. In the UK the Human Fertilization and Embryology Act came to allow that children conceived after April 6, 2009 may have two female parents, appearing both women as mothers on the birth certificate and both designated as "parents," without reference to the legal father (Gamble, 2008/2009; McCandless \& Sheldon, 2010). Other jurisdictions hypothesize three parents (tri-parenthood), as is the case of New Zealand (New Zealand Law Commission, 2005), where a proposal was presented to legally recognize a child born by artificial insemination as having three parents, including the donor. In Canada, in the case AA v BB \& CC (2007) ONCA 2, a Court of Appeals in Ontario issued a declaration of motherhood in favor of a lesbian woman, considered as the third parent of her partner's 
biological daughter (Radbord, 2010).

Despite the relevance of genetic ties, the modern legal rules on filiation give more prevalence to the emotional and social bonds than to the biological one, as demonstrated by the legal regimes on gamete donation and surrogacy (when admitted), which clearly underline the desire to raise and love the child.

Nevertheless, even when reasoning in the exclusive context of genetic contribution, the fact is that the input of the mitochondrial donor is negligible in the overall picture of the genetic code of the person so born. While each gamete donor (sperm and oocytes) is responsible for $50 \%$ of the nuclear genetic makeup of the child, mitochondrial donation contributes with a negligible amount of DNA. Although a minimum threshold of genetic contribution required to establish parentage has not been fixed - because the phenomenon of having several contributions at the gametic level is quite new - certainly a genetic contribution that low, furthermore devoid of the intention to establish filiation ties, cannot sustain the maternity bond (Nuffield Council On Bioethics, 2012).

In sum, despite the donor's intervention, it is not accurate to state that the child has three genetic parents. The contribution of the mitochondrial donor is much closer to the one of an organ donor than to a supposed genetic third parent. Indeed, the child will inherit between 20000-30000 genes from paternal sperm and maternal oocytes, whereas mitochondrial donation transmits only 37 genes (next to a small mitochondrial contribution from the maternal oocyte). Therefore, the nomenclature "three-parent children" is misleading.

Connected with this issue is the question of the possible disturbance on the identity of the person so born caused by the mix of genetic material (Baylis, 2011, 2013; Bredenoord et al., 2011). However, mitochondrial contribution is not enough to shape a person's identity (HFEA, 2010b). Quoting the British Department of Health (2014), "[w]e do not believe the transfer of mtDNA raises issues around identity, since it does not carry any genetic data associated with the normally accepted characteristics of identity. An analogy could be drawn with replacing the battery in a camera - the brand of the battery does not affect the functioning of the camera".

To understand otherwise equals to be trapped into genetic reductionisms, which downgrade the person to his/ her genetic makeup. Excessive geneticism has been inflamed in recent decades by virtue of some scientific advances, particularly with regard to the use of DNA for forensic purposes of research and identification, the renewed importance given to DNA testing for paternity determination, the genetic study of populations, and the consolidation of the Human Genome Project. However, this state of affairs is being opposed by a growing tendency, particularly in the field of criminology and psychology, which claims that the individual is more the product of the environment and less the product of genes. In parallel, in the legal world affiliation rules got away of purely genetic kinship in favor of a so-called social or emotional affiliation, essentially based on the desire to be a parent (Raposo, 2014; Wagner, 1995).

Even in the framework of pure genetic reasoning, the contribution of mitochondrial DNA is infinitesimal, since "it represents less than $0.054 \%$ of the total DNA, and is not part of the nuclear DNA that influences personality and other characteristics" (Anonymous, 2015).

Though the health status of a person, here dictated by mitochondrial DNA, conditions his/her personal identity, the fact is that the same can be said of the environment, education, and food, all of which factors that affect our health. In all cases we have elements, biological or not, that shape a person, to some extent turning him/her into a different individual that would otherwise exist. Mitochondrial DNA has not the power to shape the individuality of the new being as nuclear DNA does; it simply plays the role of a conditioning element.

Another argument that cannot prevail is the fear of losing the "social self" (Nuffield Council on Bioethics, 2012) due to the possible existence of two mothers. After all, today the community clearly perceives the role of the genetic material provided by donors, especially when the genetic contribution is revealed so faint as this one. This is the reason why laws do not recognize donor as parents or relatives.

Another relevant concern relates to the eventual classification of mitochondrial donation as human genetic modification, therefore subject to the limitations and prohibitions imposed by rules governing genetic manipulation. Indeed, some authors sustain that this is a form of germline genetic intervention, taking into account the modifications that it operates in the genetic heritage of the person and the effects it produces in his/her identity. Says Bredenoord: "Modification of the mtDNA is not substantively different from modification of the nuclear DNA in terms of its effects on the identity of the future person (...) the moral acceptability of germ-line modification does not depend on whether it alters the identity of the future child - all germ-line modifications do - but on whether it safeguards the child's right to an open future" (Bredenoord et al., 2011). These authors invoke the figure of the tailor-made child, stress the perils of "playing God," and underline the (although contested) right to the unmodifiability of the genetic code (Knoepfler, 2014). In contrast, other authors depart from the scope of genetic engineering to sustain that it only qualifies as such when the intervention takes place in the cell nucleus. According to the North East England Stem Cell Institute (2008), "germline gene therapy is a term used for modifying genes in the nuclear genome at the beginning of development with the intention of changing the organism in a specific way and for potentially transmitting this change to subsequent progeny. Due to the complexity of the nuclear genome, there are risks associated with modifying it, thus only gene therapy that avoids the germline is currently permitted. Replacing diseased mitochondria with healthy ones is an inherently less complicated procedure. No genome is being modified".

In fact, DNA is not modified during mitochondrial transfer, but simply transferred from a cell to another, which is not an exceptional step, since new combinations of DNA, mitochondrial and nuclear, take place in nature all over the reproductive process.

Nevertheless, even if mitochondrial transfer ends up being qualified as genetic manipulation, it must be stated that this practice is not necessarily repudiable. In fact, it is possible to sustain the legality of genetic interventions which merge into therapeutic purposes, i.e., aimed to prevent the transmission of diseases, hereditary or not (Raposo, 2014). Actually, we can go further and defend that therapeutic genetic intervention should not only be allowed, but instead, encouraged.

It can be argued that, strictly speaking, this intervention has no therapeutic character, given that preventing the birth of a person with a certain disease is different from curing that disease (Taylor, 2015). But such criticism is grounded on a limited understanding of the "therapeutic" aim and fails to take into account that in its current application in medical techniques the concept "therapeutic" encompasses every procedure related to health conditions, either to cure or prevent the occurrence of a disease.

But a caution note should be considered: mitochondrial transfer should only apply when aimed at eliminating pathological genetic notes, and not mere anomalous or unusual traits. Here lies the main issue, since it is not always 
easy to distinguish between both situations, i.e., to differentiate therapeutic interventions from the ones intended for human improvement. At first sight the answer seems (almost too) simple: in therapeutic interventions the goal is to treat or prevent the transmission of certain diseases or disabilities, whereas improvement intends to produce an human being above the regular human standard. The problem lies in the exact distinction between a disease/ disability and a mere particularity (Juengst, 1998; Parens, 1998; Raposo, 2014). Though legal theory can certainly contribute to this discussion, the distinction will be predominantly grounded on medical criteria.

Another related concern is based on the so-called slippery slope argument (Feito Grande, 1999), according to which the admissibility of mitochondrial transfer opens the door to any kind of genetic manipulation and even reproductive cloning. However, this argument fails when applied in the context of technological development. Ultimately, any scientific development would be banned if this argument were accepted, since there is always the possibility of opening the door to future developments.

Some confound mitochondrial transfer and cloning procedures. It is a fact that the technology used in both is very similar. But cloning involves the reprogramming of a cell, necessary for an adult cell to reverse to the state of embryonic cell, a step omitted in mitochondrial transfer since the oocyte enriched with the donated cytoplasm undergoes a regular fertilization process. In addition, the new being created by cytoplasmic transfer will have a unique and unrepeatable genetic code, reflecting the paternal and maternal genetic contributions, while conversely the cloned being will repeat an existing genetic code. But the crucial difference relates to the purposes of both procedures: $\mathrm{mi}-$ tochondrial transfer aims to prevent the birth of human being with mitochondrial diseases, while reproductive cloning promotes the creation of genetically identical individuals.

Mitochondrial donation has also been criticized for jeopardizing the welfare of existing people suffering from mitochondrial diseases. This argument has been used whenever technology (whether prenatal diagnosis or genetic manipulation, or even more classical procedures) allows the birth of human beings without diseases that otherwise would torment them (Raposo, 2014). But does that mean that vaccines against tuberculosis or rubella represented a lack of interest, or even a discriminatory attitude, toward people suffering from these diseases? If tomorrow Science finds a way to provide genetic protection against cancer to newborns, should we refuse such technique arguing that it turns unworthy the life of those who today suffer from various types of carcinomas (Harris, 2000, 2002)? Taken to the extreme, no one would be cured of their diseases, because treatment would be seen as a loss of interest in those who cannot be cured. The prevention of diseases cannot be confused with contempt for patients who suffer from such diseases. There is no reason to keep the birth of sick or disabled children when those conditions could have been prevented, unless we fall into the "equality of envy" (Ascensão, 2003), according to which, in order to keep all equal, all should be kept suffering.

It can be argued that this procedure is not absolutely necessary, to the extent that the same effect - birth of a child who is not a carrier of a mitochondrial disease - is achievable by other less risky means, such as PGD, gamete donation, embryo donation, or adoption (Baylis, 2013; Taylor, 2015). But in reality the effect is not necessarily the same. First, it should be noted that PGD only works with existing genetic material; therefore, the mitochondrial DNA of the reproductive technique users would be transmitted to all embryos, preventing the selection of a healthy embryo. In gamete donation - oocyte donation in our case - the born child would have no genetic link with the female element of the couple, which could be a major obstacle for some women (therefore, the argument advocated against this procedure, that it would increase the need for oocyte donation, thus increasing the level of danger for donors, cannot prevail - Nuffield Council on Bioethics, 2012; Baylis, 2013). The exact same impediment arises in embryo donation and in adoption, as both procedures cannot guarantee the aspired genetic link.

This raises the question of whether the concept of reproductive responsibility - as an obligation to prevent diseases and malformations to the offspring that may be prevented in the current state of Science - allows the imposition of limitations to reproductive rights (Raposo, 2014). In other words, what is the price to pay to have a child that is "genetically yours"?

The starting point of this analysis is the following: no one has an absolute right to having a biologically related child, regardless of requirement and limitation. The right to reproduction shall always be evaluated in conjunction with the protection of unborn human beings and the rights of born human beings. However, there is undoubtedly a natural human aspiration of having biological offspring, which is a fourth generation fundamental right (Raposo, 2012). Therefore, people cannot be forced to abdicate the right of having a genetic child - thus depriving themselves of a fundamental right - solely on behalf of hypothetical and uncertain risks, whose demonstration is far from evident.

Another concern relates to an unlawful modification in human nature, as the genetic code of this new being is transmitted to future generations to become part of the genetic pool of humanity. While somatic genetic interventions (which affect only the individual) have enjoyed some tolerance, the same is not true for germinal genetic interventions (which are transmitted to future generations). Changing the gene pool via human effort has aroused criticism.

However, is genetic heritage immutable (Bredenoord et al., 2011; Raposo, 2014)? Is Science not allowed to modify the genome designed by nature, no matter how aberrant its consequences are for the person and his/her offspring? The random recombination of the forces of the universe is imperatively more legitimate than genetic intervention?

The human genome cannot be sanctified. Law cannot hide behind a supposed genetic immutability to prevent scientific advances whose purpose is to improve our quality of life (Ascensão, 2003; Raposo, 2014). The right to inherit an unchanged genetic code cannot override the right to inherit a healthy gene pool, as follows from the right to health and the right to physical integrity.

Moreover, the mitochondrial contribution will be diluted over subsequent generations, even more so because transmission occurs solely via the maternal route.

It must also be stressed that this is a very small genetic change within the vast human genetic code, in which the mitochondrial genome plays a distinctively minor role. Our conclusion is not based on the amount of genes involved, as the relevance of the change does not relate to the quantity but rather to the functions associated with those genes. In fact, it may be that an intervention in a small number of genes might produce decisive changes for an individual, as is the case with changes to the $\mathrm{Y}$ chromosome, which contains only 86 genes, but defines the person's gender (Nuffield Council On Bioethics, 2012). However, while mitochondrial DNA interacts in different ways with nuclear DNA, its contribution to the human genetic code is negligible and unable to dictate any of our characteristics, but to improve our health.

A legitimate practice?

Despite the possible risks of mitochondrial donation, it 
must be stressed that we are talking about purely hypothetical risks. In short, many of these fears are grounded on risks that will probably never materialize.

The risks involved are not, after all, that different from the risks inherent to any new technology or even to human reproduction. The mere fact of having a child, be it through sexual intercourse or with the aid of "technical interference", is always a risky procedure, and one can never know in advance (at least before the first prenatal tests) whether the child will be healthy, much less if he/she will remain healthy (or relatively healthy, at least) during his/ her entire life. So, strictly speaking, the question is not whether this procedure is risk-free - a goal virtually impossible to achieve - but rather if the magnitude of such risks and their probability of occurrence may be justified by the expected benefits.

Not even the experimental nature of a procedure should be an argument strong enough enough to outlaw it. Every consolidated technique begins with an experimental procedure and will remain as such if not implemented. Therefore, the solution is not to prohibit it, but to put into effect the principles of prevention and precaution (Ballesteros, 2007; Romeo Casabona, 2003), to thus introduce the required precautions and foster further investments in research.

Furthermore, we must have in mind the utmost importance of the pursued aim, intrinsically linked to the principle of medical and scientific beneficence, or more properly to an idea of procreative beneficence, since the goal is to avoid the birth of children with severe and potentially fatal diseases (Gorman et al., 2015), with no plausible risk to the child (Anonymous, 2015). Doing nothing and allowing the birth of children so significantly impaired would be a violation of medical rules and legal basic principles.

\section{Analogies between the regulation of oocyte donation and mitochondrial donation}

Once mitochondrial donation is admitted it will require its own regulations. Although such rules may seek inspiration in the legal regime of gamete donation for reproduction purposes (note that the rights and responsibilities of these donors differ from those who donate gametes for research), they cannot be absolutely identical; instead, they must take into account the specificities of each procedure.

In terms of similarities, the first point to be noted is the removal of legal maternity from the donor, since the norm around the world is that legal parenthood never lies with the donor (Raposo, 2014).

A solution that we can discuss is the anonymity/nonanonymity duality and the analysis of whether the principles applicable to oocyte donors translate well to mitochondrial donors. Europe is divided between anonymity and non-anonymity, the former still leading legal preferences despite growing controversy. In jurisdictions in which the person so born is allowed access to the identity of the donor, as in the UK (by means of the Human Fertilization \& Embryology Authority, Disclosure of Donor Insemination Regulations, 2004, S.I. 2004/1511), should this solution also apply to mitochondrial donations and should the person so born be able to contact the donor and other children who share the same mitochondrial donation (HFEA, 2010a)?

The point is that the reasons that drive someone to find the identity of an oocyte donor - namely the wish to satisfy the rights to genetic and personal identity - are hardly valid within the context of mitochondria donors, whose involvement contributes nothing to one's physical and psychological characteristics (Wellcome Trust, 2014). Mitochondria do not define who we are as persons; therefore, it is more difficult to sustain that knowing the do- nor's identity might complete the knowledge about one's self.

The very motivation of those who use each one of these procedures - oocyte donation and mitochondria donation - may dictate differences in the regulatory system of anonymity. The reason is that mitochondrial donation will be used precisely for those who want to ensure a genetic link with the offspring, an aspiration absent in oocyte donation. Actually, oocyte donation is the alternative to mitochondrial donation for those who do not mind losing the genetic link with the offspring. Therefore, it is possible to sustain that, by reducing the genetic intervention of third parties to a minimum, the receivers of mitochondria donation wish to ensure the anonymity of the donor's intervention, an aspiration difficult to sustain for those who apply to more intrusive genetic interventions (Nuffield Council on Bioethics, 2012).

Nonetheless, in view of the purpose of maximizing the preservation of the genetic code that the child would have if not for the mitochondrial donation, there are good reasons to sustain that the donor should not be a stranger, but rather a close relative of the patient (the genetic mother). This will rarely be possible because chances are that all women genetically related to the mother will have the same mitochondrial mutation, but whenever possible this might be an option to consider. Lawmakers should analyze whether anonymity should be given up for the sake of the preservation of the genetic code.

Another possible parallelism between oocyte donation and mitochondrial donation relates to donor compensation. The laws on gamete donation in Europe prohibit remuneration, but allow compensation strictly limited to reimbursement of expenses. The same solution should be valid to mitochondrial donation.

Despite the mentioned similitudes, let us not forget the differences. Mitochondria cannot be equated to oocytes since the roles of mitochondrial and nuclear DNA differ significantly; thus, both donations have to be treated having their particularities in mind.

\section{CONCLUSIONS}

We still cannot fully understand all the mysteries of DNA, but we can certainly go further in our investigation, in order to be able better control and use DNA to improve human health and well-being.

Despite the hypothetical risks involved, we cannot exclude mitochondria transfer from our medical practises. When faced with the possibility of having a child tormented by a serious and painful illness, feasibly with a short life expectancy, we believe that mitochondrial transfer should be allowed (Brassington, 2015).

This procedure, as well as many others involving DNA, represents one of our strongest hopes to deal with suffering and disease.

"Every time you understand something, religion becomes less likely. Only with the discovery of the double helix and the ensuing genetic revolution have we had grounds for thinking that the powers held traditionally to be the exclusive property of the gods might one day be ours..." (James D. Watson).

\section{CONFLICT OF INTERESTS}

No conflict of interest have been declared.

\author{
Corresponding author: \\ Vera Lúcia Raposo \\ Law School \\ University of Macau, E32 \\ Macau - China \\ E-mail:vraposo@umac.mo
}




\section{REFERENCES}

Anonymous. Three-parent IVF: The benefits and the risks. 19 February 2015. Available at: <http://www.medicalnewstoday.com/articles/289706.php Accessed: 15 March 2015.

Ascensão JO. Intervenções no genoma humano. Validade ético-jurídica, Revista da Ordem dos Advogados. 2003; 63: 25-49.

Ballesteros J. Biotecnología, biolítica y posthumanismo. In: Ballesteros J, Fernández E, eds.. Biotecnología y posthumanismo. Navarra: Editorial Aranzidi; 2007. p. 21-46.

Barber S, Border P. Mitochondrial donation standard note: SN/SC/6833 (Last updated: 29 January 2015). Available at: <http://www. parliament.uk/briefing-papers/sn06833. pdf Last accessed: 5 February 2015.

Baylis F. The self in situ: A relational account of personal identity. In: Downie J, Llewellyn J, eds. Relational theory and health law and policy. Vancouver: UBC Press; 2011. p. 109-31.

Baylis F. The ethics of creating children with three genetic parents. Reproductive BioMedicine Online. 2013; 26: 531-4.

Bender L. Genes, parents, and assisted reproductive technologies: ART's, mistakes, sex, race \& law. Columbia Journal of Gender and Law. Columbia J Gend Law. 2003;12:176.

Brassington I. Should parliament vote to allow "three-parent babies"? BioNews 788. 2 February 2015. Available at: <http://www.bionews.org.uk/page_491773.asp Last accessed: 17 February 2015.

Bredenoord AL, Dondorp W, Pennings G, De Wert G. Ethics of modifying the mitochondrial genome. J Med Ethics. 2011;37:97-100.

British Department of Health. Mitochondrial donation, government response to the consultation on draft regulations to permit the use of new treatment techniques to prevent the transmission of a serious mitochondrial Disease from Mother to Child. July 2014. Available at: <https:// www.gov.uk/government/uploads/system/uploads/attachment_data/file/332881/Consultation_response.pdf Last accessed: 15 February 2015.

Dong WR, Qiu XX, Chen YH, Zhao BL. Ooplasmic transfer: problems and prospects. Nan Fang Yi Ke Da Xue Xue Bao. 2006; 26: 1079-82.

Feito Grande L, ed. El sueño de lo possible. Madrid: Comillas; 1999.

Gamble N. Jumping to inclusion. Family Law Journal. 2008/2009: 9-11.

Gorman GS, Grady JP, Ng Y, Schaefer AM, McNally RJ, Chinnery PF, Yu-Wai-Man P, Herbert M, Taylor RW, McFarland R, Turnbull DM. Mitochondrial donation - how many women could benefit? N Engl J Med. 2015; 372:885-7.

Harris J. Is there a coherent conception of disability? J Med Ethics. 2000;26:95-100.

Harris J. Liberation in reproduction. In: Lee E. (ed) Designer babies: where should we draw the line? London: Hodder \& Stoughton; 2002. p. 45-60.
HFEA - Human Fertilisation and Embryology Authority. HFEA to help donor-conceived siblings contact each other. 2010a. Available at: http://www.hfea.gov.uk/5838.html . Last accessed: 10 February 2015.

HFEA - Human Fertilisation and Embryology Authority. R0153: Mitochondrial DNA disorders - Is there a way to prevent transmission? 2010b. Available at: http://www. hfea.gov.uk/1564.html\#1652 Last accessed: 5 February 2015.

HFEA - Human Fertilisation and Embryology Authority. Annex VIII: Scientific review of the safety and efficacy of methods to avoid mitochondrial disease through assisted conception: update, report provided to the Human Fertilisation and Embryology Authority. March 2013. Available at:http://www.hfea.gov.uk/docs/Mito-Annex_VIII-science_review_update.pdf Last accessed: 4 March 2015.

HFEA - Human Fertilisation and Embryology Authority. Mitochondrial Donation: An Introductory Briefing Note. October 2014. Available at: http://www.hfea.gov.uk/ docs/2014-10-01_Mitochondrial_donation_an_introductory_briefing_note_-_final.pdf Last accessed: 5 May 2015.

Juengst E. What does enhancement mean? In: Parens $E$, ed. Enhancing human traits (ethical and social implications). Washington, D.C.: Georgetown University Press; 1998. p. 29-47.

Knoepfler P. Open letter to UK parliament: avoid historic mistake on rushing human genetic modification, Knoepfler Lab Stem Cell Blog. Posted on November 2, 2014. Availabe at http://www.ipscell.com/2014/11/open-letter-to-uk-parliament-avoid-historic-mistake-on-rushing-human-genetic-modification Last accessed: 15 February 2015.

Kolata G. Babies born in experiments have genes from 3 people. The New York Times. Published May 5, 2001. Available at: http://www.nytimes.com/2001/05/05/ health/05DNA.html? module $=$ Search\&mabReward $=$ relbi as $\% 3 \mathrm{Ar} \% 2 \mathrm{C} \% 7 \mathrm{~B} \% 221 \% 22 \% 3 \mathrm{~A} \% 22 \mathrm{RI} \% 3 \mathrm{~A} 11 \% 22 \% 7 \mathrm{D}$ Last accessed: 7 February 2015.

Mccandless J, Sheldon S. The Human Fertilisation and Embryology Act (2008) and the tenacity of the sexual family form. Mod Law Rev. 2010; 73: 175-207.

New Zealand Law Commission. New issues in legal parenthood: report 88. 2005. Available at http://www.nzlii. org/nz/other/nzlc/report/R88/R88.pdf Last accessed: 15 February 2015.

North East England Stem Cell Institute. Briefing paper on the need to protect the future possibility of treating mitochondrial disease and other conditions by a procedure that involves mitochondrial transplantation. 2008. Available at: http://www.nesci.ac.uk/assets/docs/NESCIbriefon2008HFEbill-MitochondrialTransplants-Vers01-6.pdf Last accessed 12/02/2015.

Nuffield Council on Bioethics. Novel Techniques for the Prevention of Mitochondrial DNA Disorders: An Ethical Review. 2012. Available at http://nuffieldbioethics.org/wp-content/uploads/2014/06/Novel_techniques_for_the_prevention_of_mitochondrial_DNA_disorders_compressed.pdf Last accessed: 17 February 2015.

Paolo F, Gulino BM, Napoletano S, Zaami S, Frati P. The evolution of legislation in the field of Medically Assisted Reproduction and embryo stem cell research in Europe- 
an union members. Biomed Res Int. 2014; 2014:307160.

Parens E. Is better always good? The enhancement project. In: Parens $\mathrm{E}$, ed. Enhancing human traits (ethical and social implications). Washington, D.C.: Georgetown University Press; 1998. p. 1-17.

Pearson $\mathrm{H}$. Babies made by cloning-type technique die prematurely. Nature. Published online 14 October 2003. Available at: http://www.nature.com/news/2003/031014/full/ news031013-4.html Last accessed 04/02/2015.

Radbord J. GLBT Families and Assisted Reproductive Technologies. Canadian Bar Association. 2010. Available at: http://www.cba.org/cba/niagara2010/PDF/2.1_Radbord_ paper_final.pdf Last accessed: 28 March 2015.

Raposo VL. Em nome do pai (... da mãe, dos dois pais, e das duas mães). Lex Medicinae. 2007; 4: 37-51.

Raposo VL. Biodireitos: The new kids on the juridical playground. In: Correia FA, Machado JEM, Loureiro JC. eds. Estudos em homenagem ao Prof. Doutor José Joaquim Gomes Canotilho. Vol. 3. Coimbra: Coimbra Editora; 2012. p. 811-833.
Raposo VL. O direito à imortalidade (o exercício de direitos reprodutivos mediante técnicas de reprodução assistida e o estatuto jurídico do embrião in vitro). Coimbra: Almedina; 2014.

Romeo Casabona C. Los desafios jurídicos de las biotecnologias en el umbral del siglo veintiuno. In: Martínez Morán N. ed. Biotecnologia, derecho y dignidad humana. Editorial Comares: Granada; 2003. p. 45-82.

Taylor P. Three parent babies: unethical, unnecessary, unsafe. BioNews 790. 16 February 2015. Available at: http:// www.bionews.org.uk/page_497347.asp Last accessed: 15 February 2015.

Wagner WJ, eds. The contractual reallocation of procreative resources and parental rights. Aldershot, Brookfield USA, Singapore, Sydney: Darthmouth; 1995.

WellCome Trust. Q\&A:Mitochondrial donation. October 2014. Available at: http://www.wellcome.ac.uk/stellent/ groups/corporatesite/@policy communications/documents/web_document/wtp057782.pdf Last accessed: 5 February 2015. 